\title{
Influence of preparation procedure and ferric oxide nanoparticles addition on transport properties of homogeneous cation-exchange SPPO/SPVC membrane
}

\author{
FARHAD HEIDARY ${ }^{1, *}$, ALI NEMATI KHARAT ${ }^{2}$, ALIREZA KHODABAKHSHI $^{1}$ and \\ SAYED SIAVASH MADAENI ${ }^{3}$ \\ ${ }^{1}$ Department of Chemistry, Faculty of Science, Arak University, Arak 38156-8-8349, Iran \\ ${ }^{2}$ School of Chemistry, College of Science, University of Tehran, Tehran 13145-1357, Iran \\ ${ }^{3}$ Membrane Research Centre, Department of Chemical Engineering, Faculty of Engineering, Razi University, Kermanshah \\ 67149, Iran \\ *Author for correspondence (f-heidary@araku.ac.ir, heidary.farhad@yahoo.com)
}

MS received 20 May 2016; accepted 3 October 2016; published online 25 July 2017

\begin{abstract}
Homogeneous cation-exchange membranes were prepared through evaporation and phase inversion methods using sulfonated poly(2,6-dimethyl-1,4-phenylene oxide) (SPPO) and sulfonated polyvinylchloride as binders. The effect of polymers blend's ratio and preparation method on structure and electrochemical properties of the prepared membranes were evaluated. The microstructures of the membranes were investigated by scanning electron microscopy (SEM) and the sulfonation of polyvinylchloride was confirmed by elemental analyses. Moreover, the membranes performance was evaluated by ion-exchange capacity (IEC), fixed ion concentration, membrane potential, transport number, permselectivity, areal resistance, ionic permeability, flux of ions, current efficiency, membrane oxidative stability, mechanical properties and water content tests. The results indicated that IEC and water content were affected by the SPPO content and microstructures of the membranes. The results showed increased efficiency and suitable electrochemical properties for membranes prepared by the evaporation method in comparison with others. Also, $\mathrm{Fe}_{2} \mathrm{O}_{3}$ nanoparticles were synthesized at room temperature by a simple sonochemical reaction between ferric chloride and $\mathrm{NaOH}$. The results revealed that the addition of different amounts of $\mathrm{Fe}_{2} \mathrm{O}_{3}$ nanoparticles to the polymeric matrix could affect the hydrophilicity and transport properties of ion-exchange membranes.
\end{abstract}

Keywords. Cation-exchange membranes; ferric oxide nanoparticles; transport number; permselectivity; phase inversion method.

\section{Introduction}

Nowadays, ion-exchange membranes (IEMs) are intensely used in electro-membrane-based separation processes such as electrodialysis for the recovery of valuable metals from the effluents of metal-plating industry, the table salt production, separation of inorganic ions from organic mixtures, desalination of saline water, recovery of acid and base from the spent leaching solutions and for many other aims. However, the efficiency and durability of IEMs are the key factors for applications in industrial membrane processes as these factors depend on the physical and electrochemical properties [1]. To apply the membranes in harsh industrial conditions, such as high temperature, strongly oxidizing conditions, etc., developing more stable IEM is an important subject among membrane researchers. Recently, perfluorocarbon IEM was developed and successfully used under those conditions. However, it was found only in a few major applications primarily because of its high cost [2]. Poly(2,6-dimethyl-1,4-phenylene oxide) (PPO) is a polyaryl polymer which has excellent membrane-forming properties as well as suitable thermal, hydrolytic and chemical stabilities. Among the PPO derivatives, aryl substituted sulfonated PPO (SPPO) is a desired polymer which has been employed as a membrane material for gas separation, reverse osmosis, ultrafiltration and cation-exchange membranes [3-7]. The basic molecular structure of SPPO is shown in figure 1. Polyvinyl chloride (PVC) is an outstanding material because of its robust mechanical strength, low cost and excellent chemical properties (e.g., acid, alkali and solvent resistance) [8]. The $\mathrm{PVC}-\mathrm{SO}_{3} \mathrm{H}$ structures had dual properties as a sorbent, based on cation-exchange and its hydrophobicity [9]. However, blending of two polymers such as sulfonated polyvinyl chloride (SPVC) and SPPO can generate a novel structure with new properties and the membranes are expected to be ion-exchangeable and dimensionally stable. Knowledge of the membrane fabrication procedures of a particular type of membrane is a major contributing factor that could determine the electrochemical characterization of IEMs. 
The present investigation focuses on the preparation of new homogeneous IEMs based on SPPO and SPVC prepared by two different methods: evaporation and phase inversion. The purpose of this research is a comparative study of the morphological and electrochemical properties of these membranes in monovalent electrolytic solutions. A series of IEMs have been prepared based on SPPO and SPVC by two different methods. The effects of preparation methods and polymers blend's ratio (SPPO:SPVC) on electrochemical, mechanical and morphological properties of cation-exchange membranes were studied. Also, $\mathrm{Fe}_{2} \mathrm{O}_{3}$ nanoparticles were employed as an inorganic additive in membrane preparation in order to improve the physicochemical properties. Ferric oxide nanoparticles can be synthesized by a facile method and easy to incorporate with other components because of its numerous surface hydroxyl groups. The addition of $\mathrm{Fe}_{2} \mathrm{O}_{3}$ nanoparticles to the polymeric matrix could affect the hydrophilicity and transport properties of IEMs and leads to improved control of pathways for ions traffic. During the experiment, sodium chloride solutions were used as ionic feeds for the membranes characterization.

\section{Materials, instruments and methods}

\subsection{Materials}

PPO with inherent viscosity of $0.57 \mathrm{dl} \mathrm{g}^{-1}$ in chloroform at $25^{\circ} \mathrm{C}$ was obtained from Institute of Chemical Engineering of Beijing (China); SPPO was prepared by sulfonation of PPO according to the literature [10]. PVC was purchased from BIPC, Iran, grade S-7054. Tetrahydrofuran (THF) LR grade as solvent, sodium chloride and sulfuric acid (98\%) were provided from Merck Inc. Throughout the experiment, distilled water was used.

\subsection{Instruments}

Morphological investigations of the membrane surface were carried out using scanning electron microscopy (SEM) (Philips XL30) at an acceleration voltage of $25 \mathrm{kV}$. For SEM analysis, the samples were frozen in liquid nitrogen and then broken. The membrane samples were sputtered with gold and were viewed via the microscope. Elemental analyses were performed using VarioEL Series II Elemental Analyser. Fourier transform infrared (FT-IR) spectra were recorded on

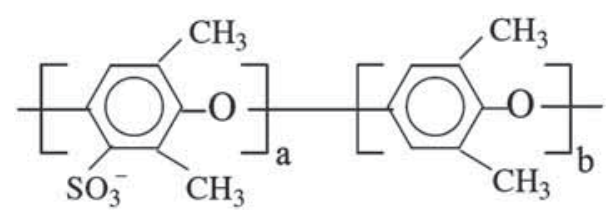

Figure 1. Molecular structure of SPPO polymer.
Galaxy series FTIR5000 spectrophotometer. X-ray diffractogram (XRD) patterns were recorded by a Philips, X-ray diffractometer using Ni-filtered $\mathrm{CuK} \alpha$ radiation.

\subsection{Sulfonation of $P V C$}

Sulfonation procedure can be performed using the following steps. Firstly, PVC powder was treated with 1,2dichloroethane for $4 \mathrm{~h}$ to swell the polymer. The pre-swollen PVC was immersed in sulfuric acid (98\%) for another $4 \mathrm{~h}$ and the mixture was stirred strongly at $60^{\circ} \mathrm{C}$. After the completion of reaction, the polymer was then rinsed several times with high amounts of deionized water to remove excess sulfuric acid and then with acetonitrile to eliminate any possible impurities. The pure PVC-SO ${ }_{3} \mathrm{H}$ polymer (SPVC) was dried at room temperature. The results of the elemental analysis indicated an increase in $\mathrm{S} / \mathrm{C}$ ratio after sulfonation process. The increment of S/C ratio from 0.0158 to 0.0864 in the modified PVC provides further evidence of functionalization of the PVC powder.

\subsection{Preparation of homogeneous cation-exchange membranes}

The membranes were prepared by dissolving the polymer binders in THF solvent. The mixture was stirred vigorously at room temperature to obtain a homogenous mixture, followed by casting it on a glass plate. Then, the membranes were dried at ambient temperature $\left(25^{\circ} \mathrm{C}\right)$ or immersed in distilled water for evaporation and phase inversion methods, respectively. Next, the samples were treated at 40, 60, 80 and $105^{\circ} \mathrm{C}$ (each temperature point lasted for $2 \mathrm{~h}$ ). At the final stage, membranes were stored in $\mathrm{HCl}$ and $\mathrm{NaCl}$ solutions, respectively. A digital calliper device was used for measuring membrane thicknesses, which confirmed that the membrane thickness was maintained at about 35-50 $\mu \mathrm{m}$. The compositions of casting solutions are shown in table 1 .

\subsection{Synthesis of $\mathrm{Fe}_{2} \mathrm{O}_{3}$ nanoparticles and nanocomposite membranes}

Two grams of $\mathrm{FeCl}_{3}$ was dissolved in $200 \mathrm{ml}$ distilled water. Then, $100 \mathrm{ml}$ of $\mathrm{NaOH}$ solution $(0.2 \mathrm{M})$ was slowly added to the solution under ultrasonic waves $(75 \mathrm{~W})$ during $30 \mathrm{~min}$. The obtained brown precipitate confirmed the synthesis of $\mathrm{FeOOH}$. The precipitate of $\mathrm{FeOOH}$ was then centrifuged and washed with distilled water, then exposed to atmosphere environment to dry. The obtained brown powder at this stage was then calcinated at $400^{\circ} \mathrm{C}$ in an oven for $3 \mathrm{~h}$. Therefore, the colour of the precipitate changed from brown to red, confirming the production of $\mathrm{Fe}_{2} \mathrm{O}_{3}$.

SEM images of $\mathrm{Fe}_{2} \mathrm{O}_{3}$ nanoparticles before and after calcination are shown in figure 2, respectively. It appears that due to calcination, a little agglomeration occurred; SEM images confirm nanoparticles with average diameter of $57 \mathrm{~nm}$. 
Table 1. Compositions of casting solutions for the preparation of homogeneous ion-exchange membrane.

\begin{tabular}{lccc}
\hline Membrane & Polymers binder & $\begin{array}{l}\text { Polymers binder } \\
\text { (SPPO:SPVC) }(\mathrm{w} / \mathrm{w})\end{array}$ & Solvent:binder (v/w) \\
\hline Sample 1 & SPPO + SPVC & $70 / 30$ & $10: 1$ \\
Sample 2 & SPPO + SPVC & $60 / 40$ & $10: 1$ \\
Sample 3 & SPPO + SPVC & $50 / 50$ & $10: 1$ \\
Sample 4 & SPPO + SPVC & $40 / 60$ & $10: 1$ \\
Sample 5 & SPPO + SPVC & $30 / 70$ & $10: 1$ \\
Sample 6 & SPPO + SPVC & $0 / 100$ & $10: 1$ \\
\hline
\end{tabular}
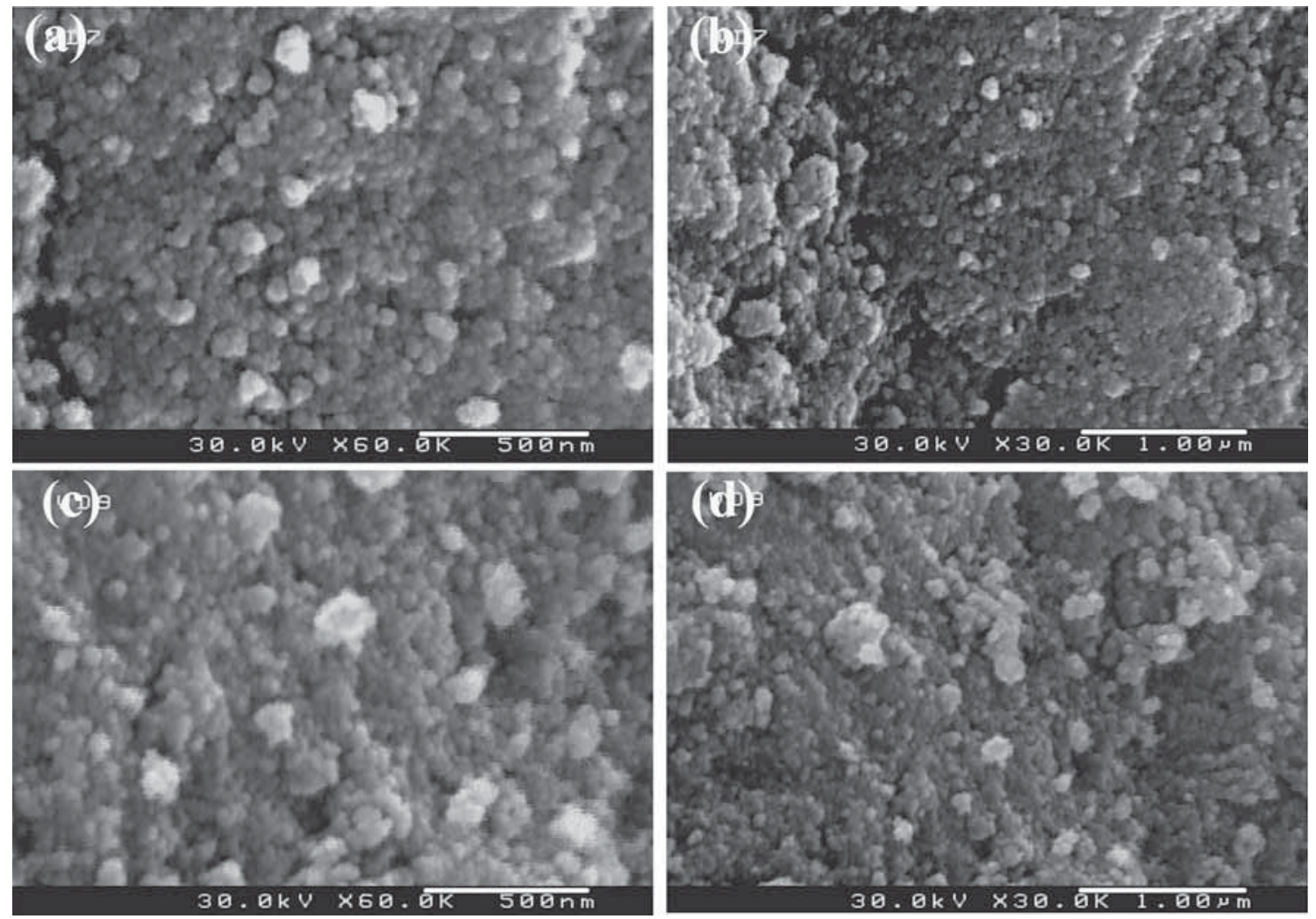

Figure 2. SEM images of ferric oxide nanoparticles $(\mathbf{a}, \mathbf{b})$ before and $(\mathbf{c}, \mathbf{d})$ after calcinations.

Figure 3 represents FT-IR spectrum of $\mathrm{Fe}_{2} \mathrm{O}_{3}$ nanoparticles and shows two absorption peaks around $454 \mathrm{~cm}^{-1}$ and $537 \mathrm{~cm}^{-1}$ correspond to the $\mathrm{Fe}-\mathrm{O}$ bond in nanoparticles. FT-IR spectrum showed that the obtained product does not exhibit any intense IR-active peak corresponding to impurities.

XRD pattern of ferric oxide nanoparticles is shown in figure 4. XRD pattern of $\mathrm{Fe}_{2} \mathrm{O}_{3}$ nanoparticles is indexed as a rhombohedral phase with space group: $R-3 c$, which is close to theliterature values (JCPDS no. 79-1741). The calculated crystallite size based on Scherrer equation is about $34 \mathrm{~nm}$.
Nanocomposite membranes were also prepared by casting solution technique. The membrane fabrication proceeded by dissolving the polymer binders (SPPO + SPVC) in THF solvent. The mixture was mixed rigorously at room temperature to obtain a homogenous mixture. A certain amount of nanoparticles was dispersed in $10 \mathrm{ml}$ THF with ultrasonic waves. The nanoparticles dispersion was then gradually added to the polymer solution. The new solution was mixed and stirred for $6 \mathrm{~h}$, followed by casting it on a clean and dry glass plate at $25^{\circ} \mathrm{C}$ and was placed at room temperature. After the evaporation, the samples were treated at $40,60,80$ and $105^{\circ} \mathrm{C}$ 


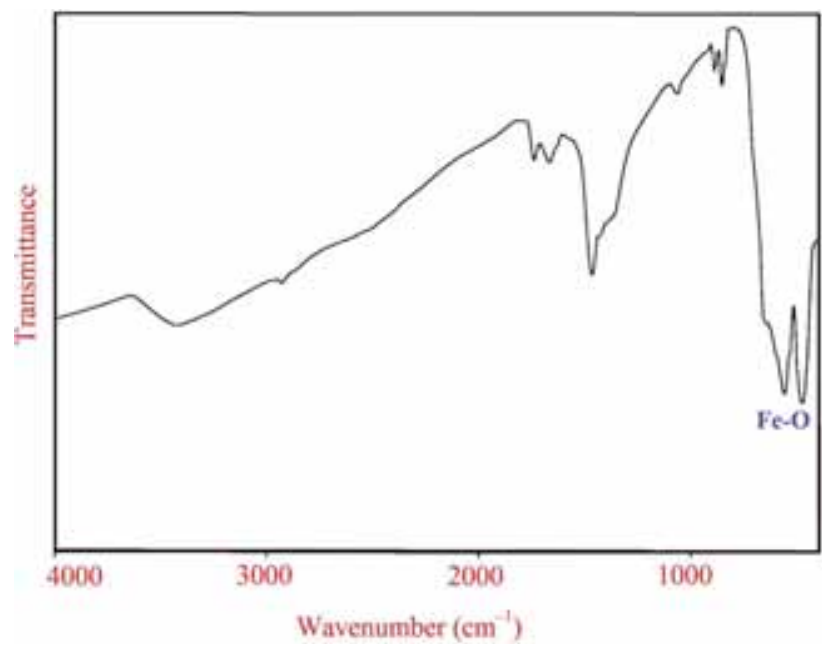

Figure 3. FT-IR spectrum of $\mathrm{Fe}_{2} \mathrm{O}_{3}$ nanoparticles.

(each temperature point lasted for $2 \mathrm{~h}$ ). Finally, nanocomposite membranes were pre-treated by immersing in $\mathrm{HCl}$ and $\mathrm{NaCl}$ solutions.

\subsection{Test cell}

The experiments were performed in a cell which was fabricated from Pyrex glass. The test cell was employed for evaluating the membrane electrochemical properties. The cell was partitioned into two cylindrical compartments (vessels, each $140 \mathrm{~cm}^{3}$ ) by inserting a piece of membrane between the electrodes as depicted in figure 5. Platinum electrodes were used as anode and cathode. The membrane was fixed between rubber rings. One side of each vessel was sealed by Pt electrode supported with a fragment of Teflon (polytetrafluoroethylene) and the other side was equipped with a piece of porous medium to support the membrane. The effective area of the electrodes and membrane was $13.85 \mathrm{~cm}^{2}$. There are two orifices on the top of each compartment for sampling and feeding aims. To minimize the influence of boundary layer during experiments and to diminish the concentration polarization on the vicinity of membrane's surface, both sections were stirred strongly by magnetic stirrers (model: Velp Sientifica Multi 6 stirrer). The schematics of experimental procedure for the preparation of cation-exchange nanocomposite membranes and transport of ions are shown in figure 6.

\subsection{Characterization of prepared membranes}

2.7a Water content: The differences in weight between the swollen and the dried membranes were used for water content evaluation. Therefore, membranes were placed in distilled water for $24 \mathrm{~h}$. Then, the water at external surfaces was wiped off with filter paper and weighed $\left(W_{\text {wet }}\right)$. Then, these weighed wet membranes were dried at fixed temperature $\left(60^{\circ} \mathrm{C}\right)$ for $4 \mathrm{~h}$ until constant weight was achieved $\left(W_{\text {dry }}\right)$ as dry-membrane. The water content can be calculated from the following equation [9]:

$$
\text { Water content } \%=\left[\left(W_{\text {wet }}-W_{\text {dry }}\right) / W_{\text {dry }}\right] \times 100 \text {. }
$$

2.7b IEC: Ion-exchange capacity (IEC) of the prepared membranes was determined through a back titration with phenolphthalein as indicator. The membranes were converted to acid form $\left(\mathrm{H}^{+}\right)$by immersion in $1 \mathrm{M} \mathrm{HCl}$ solutions for $24 \mathrm{~h}$ and then washed with enough amount of deionized water and stored in deionized water for $24 \mathrm{~h}$ until no acidity recognized in washed water by the reaction with methyl red. Next, the membranes were placed in a $1 \mathrm{M} \mathrm{NaCl}$ solution overnight to exchange all the $\mathrm{H}^{+}$with $\mathrm{Na}^{+}$and washed sufficiently with deionized water. The water consumed for washing was collected and mixed with the remaining solution. The collected

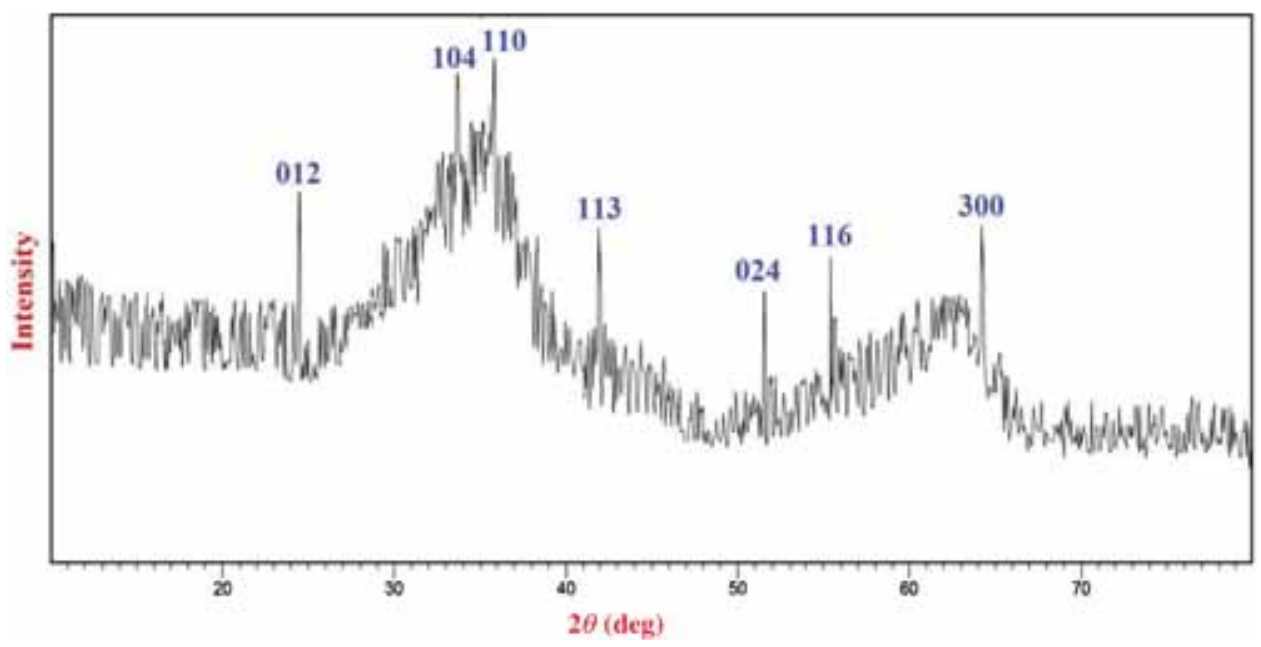

Figure 4. XRD pattern of $\mathrm{Fe}_{2} \mathrm{O}_{3}$ nanoparticles. 


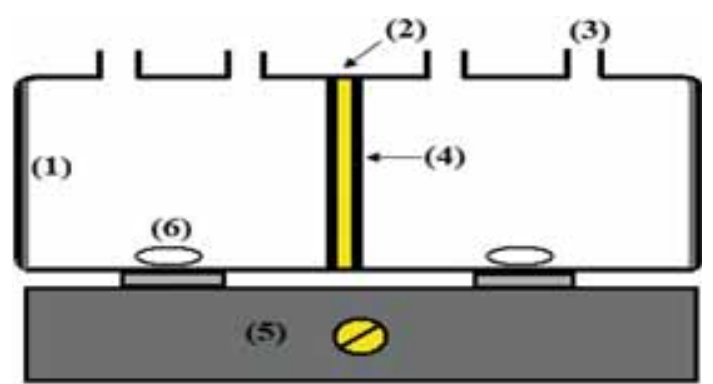

Figure 5. Schematic diagram of test cell: (1) Pt electrode, (2) magnetic bar, (3) stirrer, (4) orifice, (5) rubber ring and (6) membrane.

solution was titrated against a standard $0.01 \mathrm{M} \mathrm{NaOH}$ using a phenolphthalein as the end point indicator (a meq). Finally, the membrane was dehumidified with filter paper and dried in oven at $60^{\circ} \mathrm{C}$ for $4 \mathrm{~h}$ and then weighed $\left(W_{\mathrm{gr}}\right)$. The IEC can be calculated from the following equation [11]:

$$
\operatorname{IEC}=(a / W)
$$

2.7c FIC: The ratio of IEC to water content is defined as fixed ion concentration (FIC) which can be calculated by:

$$
\text { FIC }=\text { IEC/water content. }
$$

2.7d Membrane potential, transport number and permselectivity: The membrane potential is algebraic sum of Donnan and diffusion potentials determined by the partition of ions into the pores as well as the mobilities of ions within the membrane phase compared with the external phase [12-14]. The membrane potential was evaluated in a two-cell glassy apparatus, in which a circular membrane of $13.85 \mathrm{~cm}^{2}$ effective area was embedded between the cells and divided into two $\mathrm{NaCl}$ solutions of concentrations 0.01 and $0.1 \mathrm{~mol} \mathrm{dm}^{-3}$. After $10 \mathrm{~min}$, the developed potential $\left(E_{\mathrm{m}}\right)$ across the membrane was evaluated at room temperature using two $\mathrm{Ag} / \mathrm{AgCl}$ electrodes located near both the membrane solution interfaces for the direct potential measurement without the ohmic drop. The potential was measured by a digital auto multi-meter. The membrane potential developed between the solutions contacting with both membrane surfaces is expressed by the Nernst equation, which was used to estimate the transport number of ions as follows:

$$
E_{\mathrm{m}}=\left(2 t_{\mathrm{i}}^{\mathrm{m}}-1\right)(R T / n F) \ln \left(a_{1} / a_{2}\right),
$$

where $t_{\mathrm{i}}^{\mathrm{m}}$ is transport number of counter-ions in membrane phase, $R$ is gas constant, $T$ the temperature, $n$ the electrovalence of counter-ion and $a_{1}, a_{2}$ are electrolyte activities in the solutions in contact with both sides of the membrane determined by Debye-Huckel limiting law. The ionic permselectivity of membranes is quantitatively expressed based on the migration of counter-ions through the IEMs [15-17].

$$
P_{\mathrm{s}}=\left(t_{\mathrm{i}}^{\mathrm{m}}-t_{0}\right) /\left(1-t_{0}\right),
$$
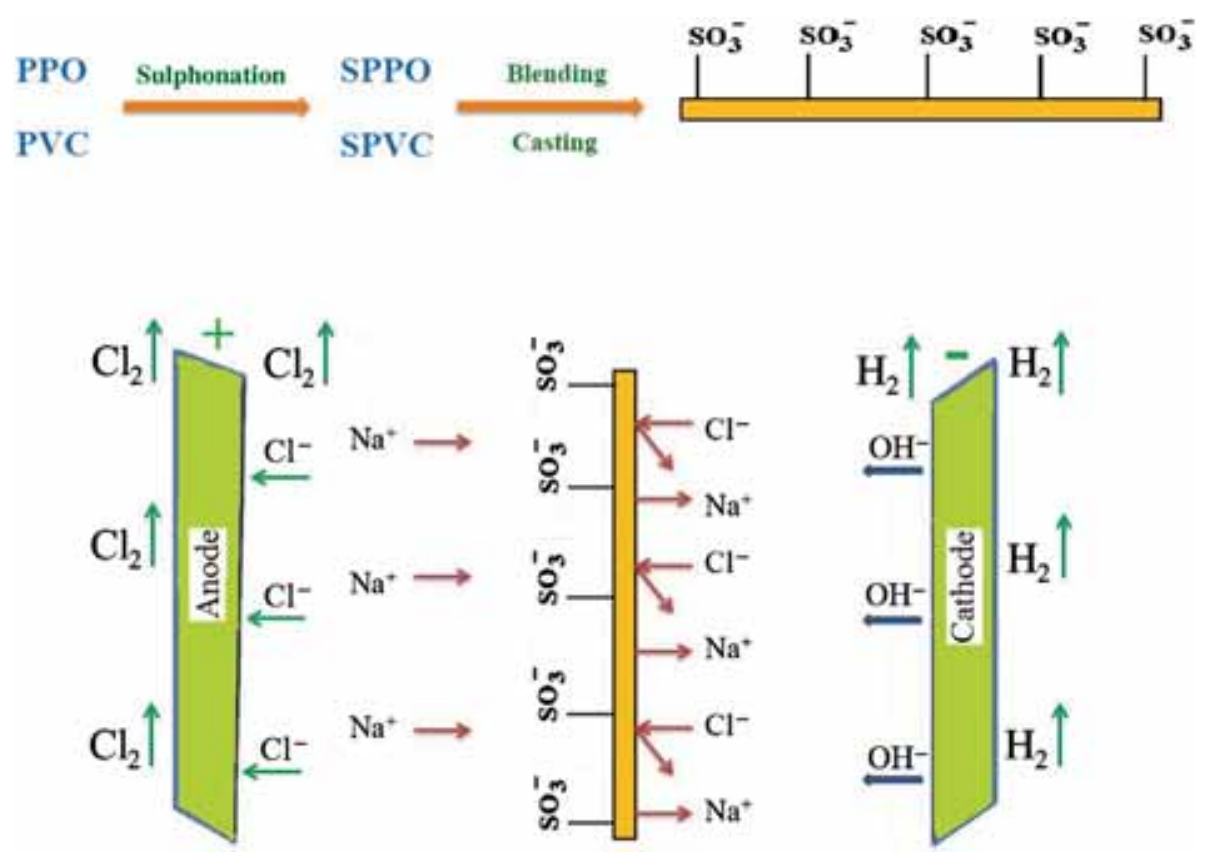

Figure 6. Schematic diagram of cation-exchange membranes preparation and transport of ions. 
where $t_{0}$ is the transport number of counter-ions in solution phase.

2.7e Concentration of fixed charge on the membrane surface: By generating of more conducting areas on the membranes surface, their electrochemical properties may be improved by homogeneity and uniform distribution of functional groups on the surface of membranes. The uniform electrical field intensity around the membrane can also be strengthened and the concentration polarization phenomenon may be diminished by the presence of more conducting zones on the surface of membrane. The concentration of fixed charge on the membrane's surface $(Y)$ has been shown based on permselectivity as follows [18,19]:

$$
Y=\frac{2 C_{\text {mean }} P_{\mathrm{s}}}{\sqrt{1-P_{\mathrm{s}}^{2}}}
$$

2.7f Ionic permeability and flux of ions: Measurements of ionic permeability and flux of ions were performed using test cell. For this purpose, one side of the cell was fed with $0.1 \mathrm{M}$ $\mathrm{NaCl}$ solution and its other side with a $0.01 \mathrm{M}$ solution. Two stable platinum electrodes that are connected to the end of the compartments were used for applying a DC electrical potential (Dazheng, DC power supply, Model: PS-302D) with optimal constant voltage across the cell. By applying the electrical potential during the test, cations $\left(\mathrm{Na}^{+}\right)$permeate through the membrane to the cathodic compartment. Also, according to the following reactions, $\mathrm{pH}$ of this zone is increased due to hydroxide ions production in the cathodic section. To calculate the transported cations through the membrane, the number of produced hydroxide ions in the cathodic section can be used. Therefore, the $\mathrm{pH}$ change in the cathodic region is a measure of the permeation of ions $(\Delta n)$ through the membrane network. The changes in $\mathrm{pH}$ with time were measured with the help of a digital pH meter (Jenway 3510).

$$
\begin{aligned}
& 2 \mathrm{Cl}^{-} \rightarrow \mathrm{Cl}_{2} \uparrow+2 \mathrm{e}^{-} \quad \text { (Anodic reaction), } \\
& 2 \mathrm{H}_{2} \mathrm{O}+2 \mathrm{e}^{-} \rightarrow \mathrm{H}_{2} \uparrow+2 \mathrm{OH}^{-} \quad \text { (Cathodic reaction). }
\end{aligned}
$$

To ensure the equilibrium condition in two solutionmembrane interfacial zones and to minimize the effect of boundary layers, both sections have been mixed strongly with magnetic stirrers [18,19].

2.7g Electrical resistance and current efficiency: The measurement of membrane resistance was performed because it performs a substantial role in the operative application of IEMs. The resistance of membranes in the $0.5 \mathrm{M} \mathrm{NaCl}$ solution was measured at ambient temperature. A membrane sample was soaked in a $0.5 \mathrm{M} \mathrm{NaCl}$ solution for $24 \mathrm{~h}$ and then washed with distilled water. Then, the membrane was embedded into the cell. The cell compartments were filled with $\mathrm{NaCl}$ solution $(0.5 \mathrm{M})$ at $25^{\circ} \mathrm{C}$. The electric resistance $\left(R_{1}\right)$ was measured by an alternating current bridge with the frequency of $1500 \mathrm{~Hz}$ (Audio signal generator, Electronic Afzar Azma Co. P.J.S). In the next step, the apparatus was re-assembled without a membrane, and the electric resistance $\left(R_{2}\right)$ was measured. The membrane resistance can be calculated from the difference between $R_{2}$ and $R_{1}\left(R_{\mathrm{m}}=R_{1}-R_{2}\right)$. The areal resistance was expressed as follows [18-20]:

$$
r=\left(R_{\mathrm{m}} A\right)
$$

where $r$ is areal resistance and $A$ the surface area of the membrane.

The current efficiency (CE) can be expressed by the following equation [13]:

$$
\mathrm{CE}=\frac{F \times Z_{\mathrm{i}} \times \Delta n}{\int_{t=0}^{t=t} I d t},
$$

where $Z_{\mathrm{i}}$ is the valance of ion, $F$ the Faraday constant, $\Delta n$ is transport number of moles and $I$ the current intensity.

2.7h Membrane oxidative stability: Strips of dry samples were dipped in $3 \% \mathrm{H}_{2} \mathrm{O}_{2}$ aqueous solution containing $4 \mathrm{ppm}$ $\mathrm{Fe}^{3+}$ at $25^{\circ} \mathrm{C}$ for up to $60 \mathrm{~h}$. The weight of the dried samples (dried at $60^{\circ} \mathrm{C}$ for $4 \mathrm{~h}$ ) before and after the experiment was measured (using Mettler Toledo Group, Model: AL204). The percentage of the decreased weight can be attributed to the membrane oxidative stability [19,21].

2.7i Mechanical properties: The measurements were performed on strips of membranes ( $50 \mathrm{~mm} \times 5 \mathrm{~mm}$ dimension), using a tear tester (Elmendorf, model: 83-20) in a wet state at room temperature. To obtain accurate results, at least three specimens from each sample were tested and the average values were reported.

2.7j Hydrophilicity: The static contact angle between water and membrane was measured at room temperature using a contact angle measuring instrument (KRUSS, G10, Germany) for the evaluation of the membrane hydrophilicity. Deionized water was used as the probe liquidin all measurements. To minimize the experimental error, the contact angle was measured at four random places for each membrane and then the average was reported.

\section{Results and discussion}

\subsection{IEC}

IEC results of the prepared membranes are represented in figure 7. The results showed an improvement in IEC by increment of SPPO:SPVC ratio in casting solution. This can be due to the enhancement of membranes functional groups as a result of higher SPPO content. 


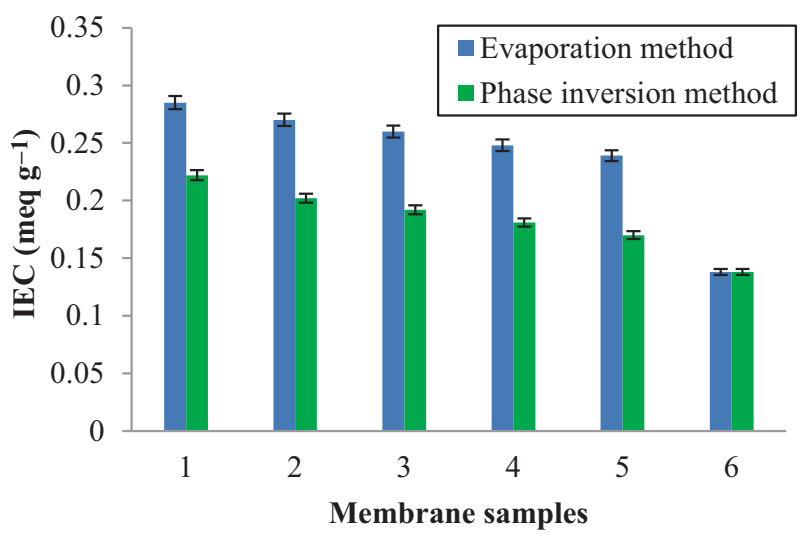

Figure 7. Effect of preparation method and blend ratio of polymers binder on IEC of prepared membranes.

According to figure 7, the IEC of evaporation method samples was higher than phase inversion method samples. This may be attributed to solubility of binders in water during the phase inversion method. Actually, the decreasing of IEC in the phase inversion samples was occurred due to the loss of the SPPO contents as the ion-exchange part. Thus, the functional groups in phase inversion samples were lower than others. But as can be expected, fabricated membranes with pure SPVC (sample 6) have the same IEC in two ways and the preparation method has no effect on their property.

\subsection{Water content}

Effect of SPPO:SPVC ratio in casting solution on water content is shown in figure 8. The increment of SPPO:SPVC ratio in casting solution led to an increase in water content due to the hydrophilicity of SPPO and the increment of functional groups in the membrane matrices [3]. However, the water content of prepared membranes by phase inversion was comparatively low. The water content amount can be correlated with the cavities and voids in the membrane matrix. In the membranes prepared by phase inversion method, decrease in cavities has been observed (figure 9). This can be attributed to polymers phase separation (as a result of solubility difference of binders in the water) which caused more impaction in each phase compared to the phase generated by two different polymers. The cross-sectional and surface SEM images of membranes showed apparently the phase separation of the binders in phase inversion method (figure 9c, d). Also, the prepared membrane by evaporation method at 50:50 (sample 3 ) blend ratio exhibited higher water content than membrane with 60:40 (sample 2) composition. This can be justified on the basis of the formation of more vacant space (voids and cavities) in the membrane structure with 50:50 (SPPO:SPVC) composition in comparison with 60:40 (SPPO:SPVC) blend ratio.

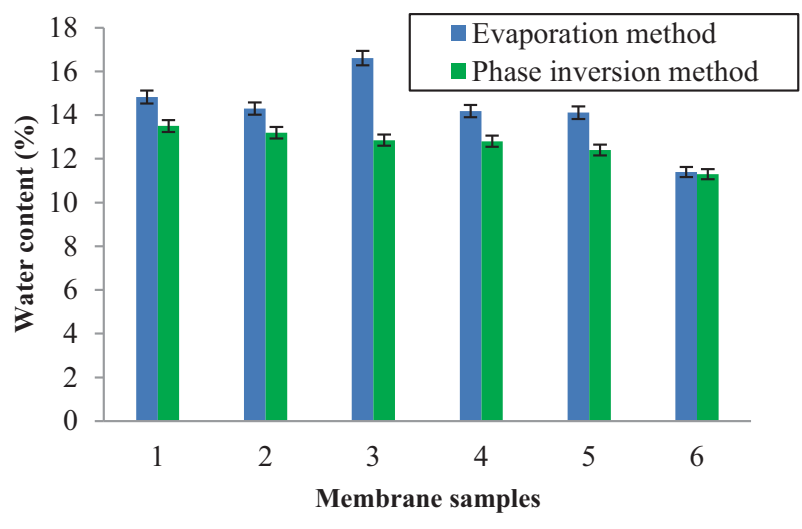

Figure 8. Water content of prepared membranes.

\section{$3.3 \quad F I C$}

FIC or the equivalent of functional group per absorbed water content can be used for electrochemical characteristics of IEMs. Figure 10 exhibits the FIC for the prepared membranes. The membranes with both methods at 70:30 (SPPO:SPVC) composition have exhibited relatively a desirable FIC compared to others. This observation is attributable to the high relative IEC for these samples. Also the FIC values of phase inversion method samples were less than evaporation method samples. This is due to the lower IEC of phase inversion method samples. However, sample 3 which was prepared by evaporation method had a lower FIC value compared to phase inversion method sample due to its high water content.

\subsection{Permselectivity and transport number}

Permselectivity and transport number of membranes are shown in figures 11 and 12, respectively. For the phase inversion method samples, the permselectivity and transport number of membranes were gradually decreased with decreasing SPPO content from samples 1-6. This may be attributed to decreasing of IEC and functional groups which leads to diffuse of counter and co-ions through the membrane.

Moreover, for the evaporation method samples the permselectivity and transport numbers were decreased from samples 1-6, but for the sample with 50\% SPPO (sample 3), these properties were rather low. This can be explained by high swelling for sample 3, which led to higher diffusion of the co-ions through the membrane compared to samples 4 and 5 [22]. Also, the low ionic sites concentration facilitates the passage of co-ions across the membrane and reduces the selectivity [3].

Moreover, the permselectivity and transport numbers of the evaporation method samples were higher than phase inversion method samples. It can be attributed to the suitable distribution of functional groups and higher miscibility of binders in the evaporation method samples. Appropriate mixing leads to uniform distribution of functional groups on the membrane 

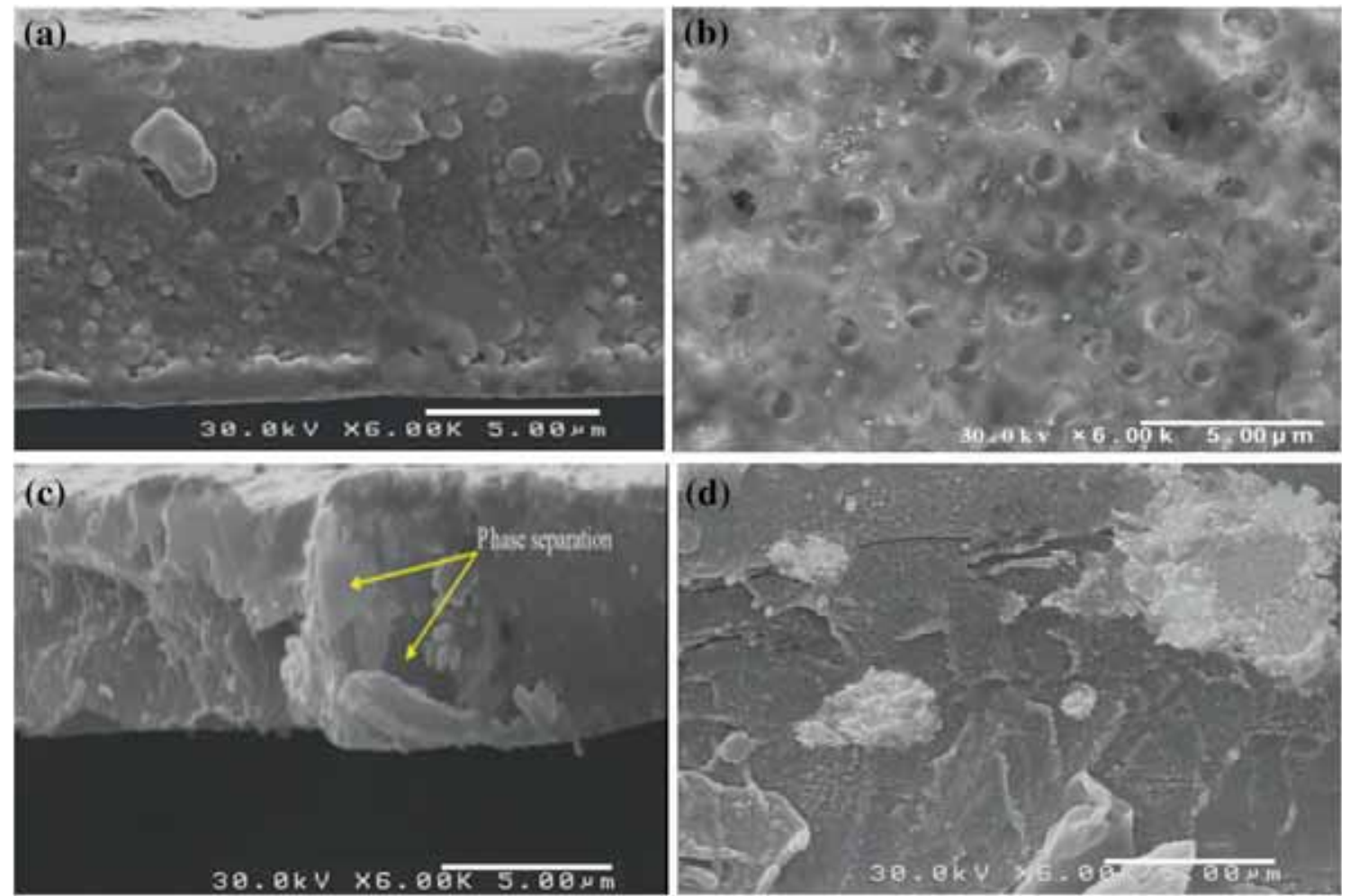

Figure 9. Cross-sectional and surface SEM images of prepared membranes with 50:50 polymers blend ratios (SPPO:SPVC). (a, b) Evaporation method and (c, d) phase inversion method.

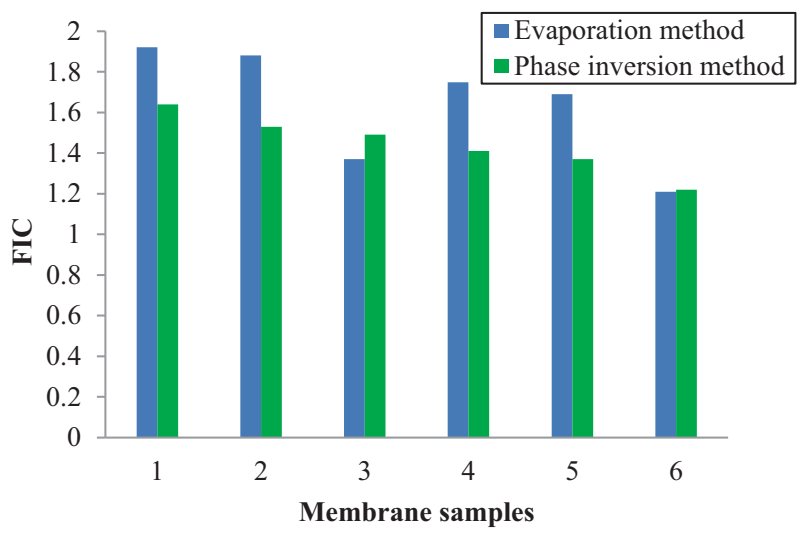

Figure 10. FIC of prepared membranes.

surface and provides the more relative conducting areas that can enhance the intensity of the uniform electrical field around the membrane [23].

\subsection{Membrane potential and surface charge density}

Figure 13 shows the variations of the membrane potential as a function of membrane composition and preparation method. The curves indicated a behaviour similar to FIC values. The potential values of phase inversion method samples were

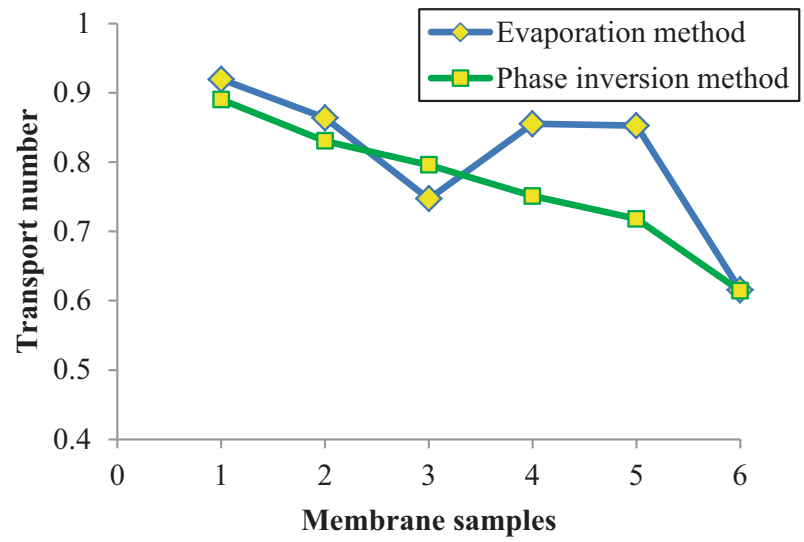

Figure 11. Transport number of prepared membranes with different preparation methods.

lower than evaporation method samples (except for sample 3 ), which were compatible with FIC values.

The decrease in FIC values of the prepared membranes (figure 10) leading to surface charge density decline (figure 14) and therefore, the conducting areas in the membranes are diminished. This leads to decrease in Donnan exclusion, which is responsible for decline in membrane potential [12-14]. 


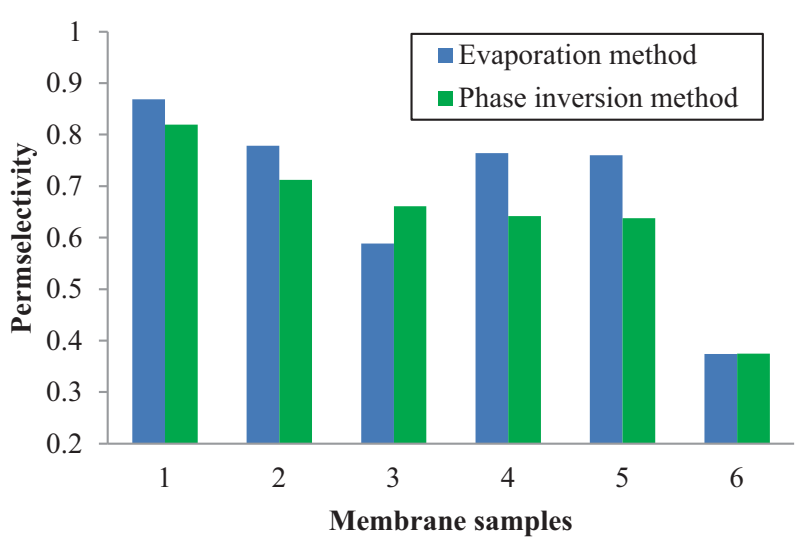

Figure 12. Permselectivity of prepared membranes with different preparation methods.

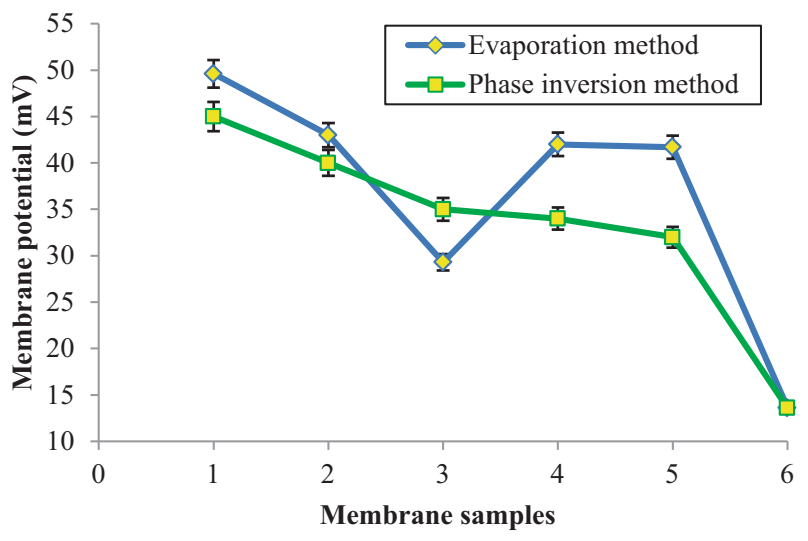

Figure 13. Membrane potential of the prepared membranes.

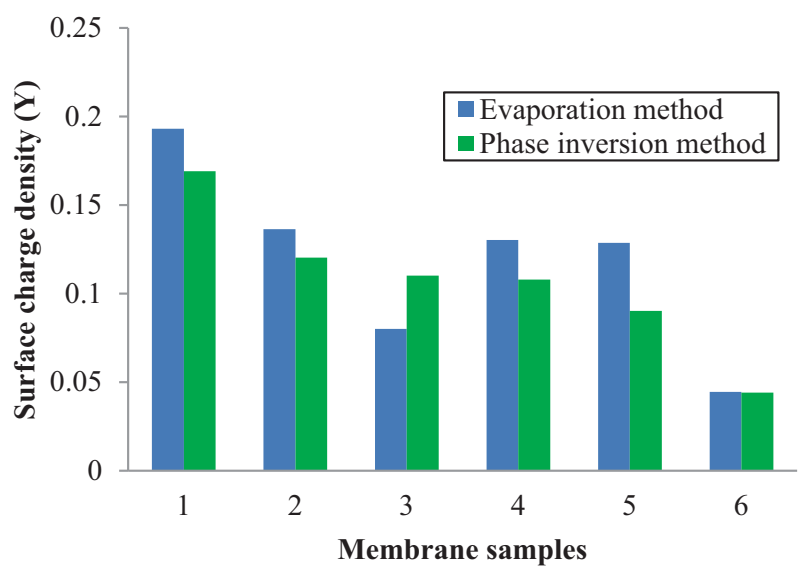

Figure 14. Surface charge density of the prepared membranes.

Also, the existence of greater conducting regions on the surface of membrane can strengthen the intensity of uniform electrical field around the membrane, which decreases the concentration polarization phenomenon [23].

The prepared membrane with evaporation method at 50:50 (SPPO/SPVC) blend's ratio exhibited a lower potential in comparison with prepared membrane by phase inversion method at the same composition. This can be due to more impaction in the membrane matrix and less free cavities in the body of the prepared sample via phase inversion method as shown in SEM images (figure 9), which leads to enhanced membrane potential and hindrance of co-ions transition [3].

In general, similar sequences were observed for permselectivity, transport number, FIC and membrane surface charge density values. By the increment of FIC due to the presence of enough ionic functional groups and proper amount of water content, further control on pathways of ions transport can take place and vice versa. The excessive homogeneity and uniform distribution of functional groups in the network of membrane and the membrane surface provides superior conducting regions in membrane and generates suitable flow channels for the counter-ions permeation and so they improve the membrane electrochemical properties [19].

\subsection{Ionic permeability and flux}

During the test, cathodic section is concentrated gradually with sodium ions which pass through the membrane and reach to cathodic section. The variations of conductivity in concentration section are shown in figure 15. The results showed conductivity improvement during the test time for all the prepared membranes. The results also showed that for some samples (samples 3 and 6) the rate of conductivity improvement with time was very low. Figure 16 indicates $\mathrm{pH}$ values in cathodic section at the end of the experiment. The results of flux and ionic permeability were calculated from $\mathrm{pH}$ changes in cathodic region.

In phase inversion samples, the ionic permeability and flux of ions (figures 17 and 18) were diminished with decreasing the SPPO:SPVC ratio due to decline in IEC and surface charge density. Therefore, lower number of ions transferred through the membranes. Also, the phase inversion membranes showed lower ionic permeability and flux compared to evaporation method membranes.

For the evaporation method samples, the obtained results also revealed that the permselectivity and transport numbers were decreased from samples 1-6 (except for sample 3). For the sample 3, due to the decline in membrane IEC and low concentration of fixed charges on the membrane surface, low permeability and flux were seen [24]. The ionic permeability and flux values of sample 6 were very low due to negligible values of membrane's IEC and surface charge density.

In general, the variations in flux and ionic permeability were compatible with surface charge density and membrane potential trends. High intensity of uniform electrical field around the membrane can be achieved as a result of sufficient surface charge which leads to the improvement of the ionic pathways. As a result, the membrane conducting regions are improved and so excellent electrostatic interactions of ions with membrane surface can take place during the process. This simplifies the ions transfer and increases the permeability and flux. 

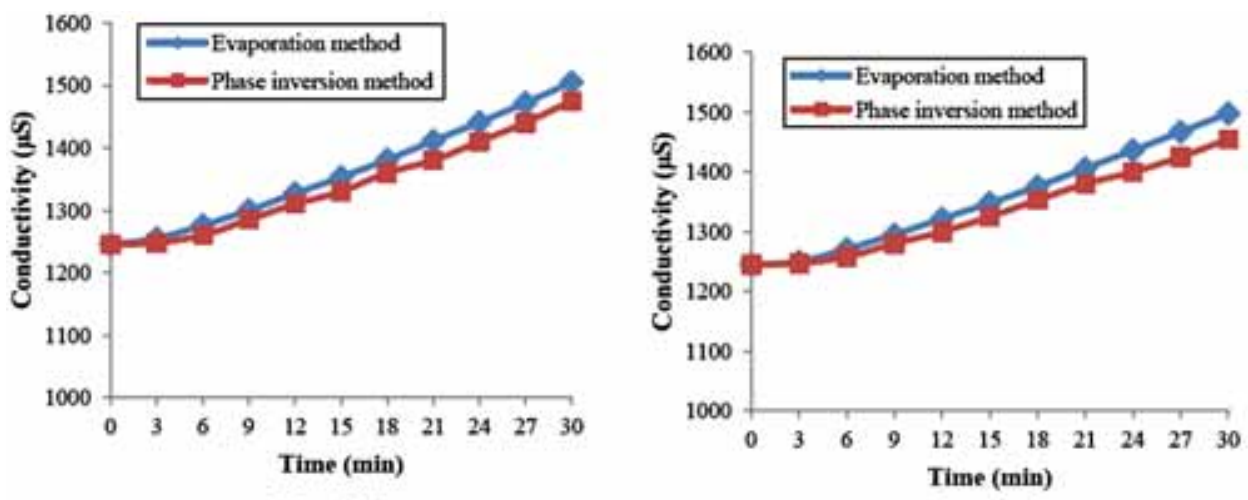

Sample 1

Sample 2
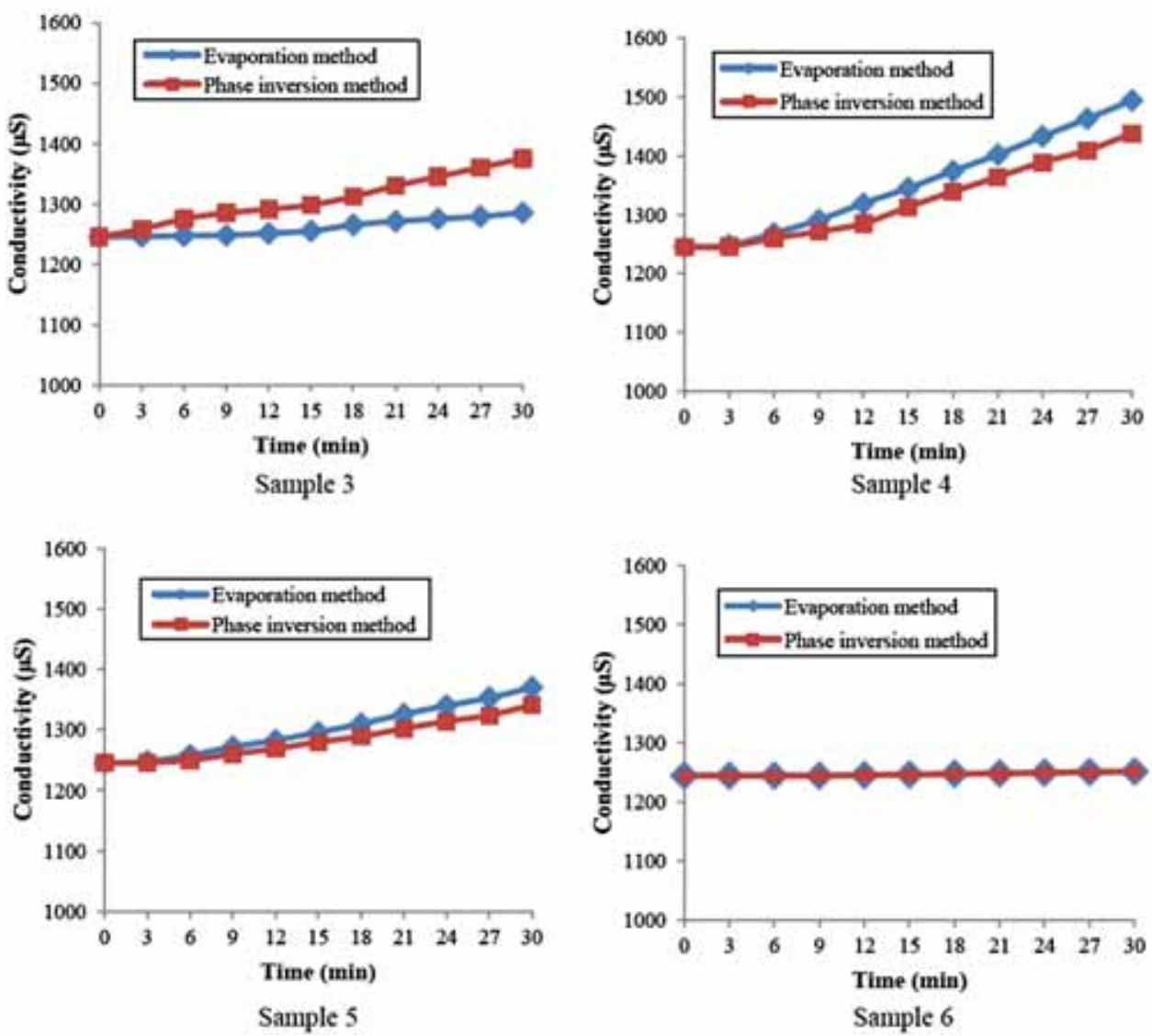

Figure 15. Variations of conductivity with time in permeate section for the prepared membranes.

\subsection{Membrane oxidative stability}

Table 2 lists the oxidative stabilities of the prepared membranes. The oxidative stabilities of the membranes were influenced by the water uptake and the SPPO content. The increase in IEC and water diffusion results in higher possibility of oxidant's diffusion in the membranes structure and more weight loss during the experiment [3]. The phase inversion membranes showed higher oxidative stability compared to evaporation method membranes due to decrease of SPPO and water content. For two methods, the membrane containing $100 \%$ SPVC had the most oxidative stability value (the least weight loss value). For the sample prepared with evaporation method at 50:50 (SPPO:SPVC) composition (sample 3 ), the high weight loss can be attributed to its water absorption characteristic which results in high oxidant's diffusion in the membrane network.

\subsection{Mechanical properties}

Effect of blend's ratio (SPPO:SPVC) and membrane preparation method on mechanical properties of prepared membranes is shown in figure 19. For two methods the mechanical 


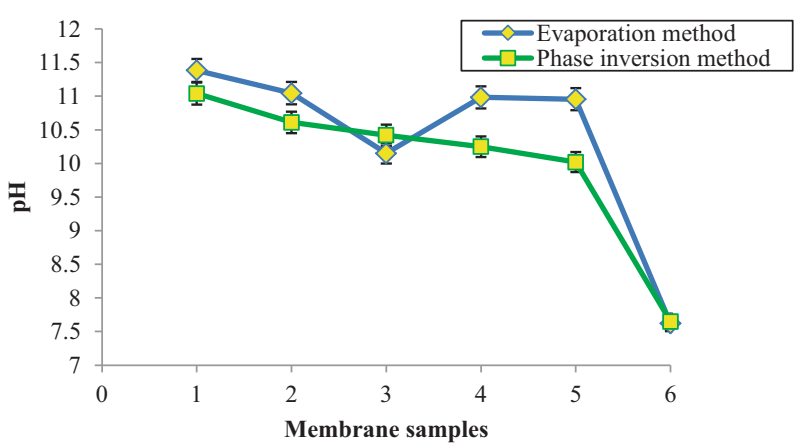

Figure 16. Variations of $\mathrm{pH}$ in cathodic section at the end of experiment (initial $\mathrm{pH}=7.536$ at ambient temperature).

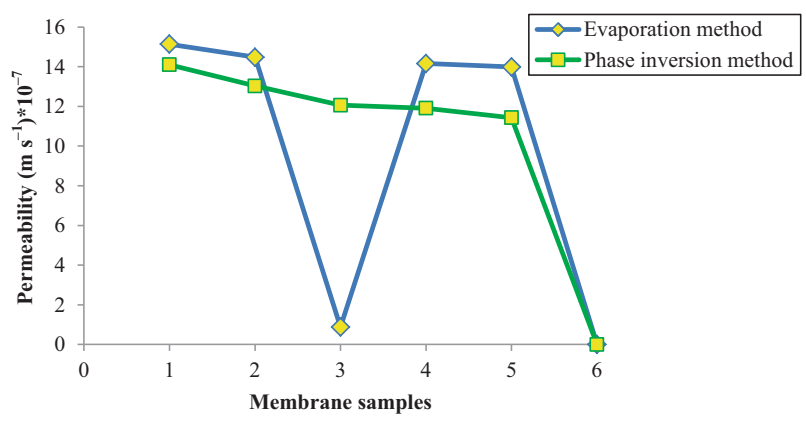

Figure 17. Effect of preparation method and blend ratio of polymers binder (SPPO:SPVC) on ionic permeability of cation-exchange membranes.

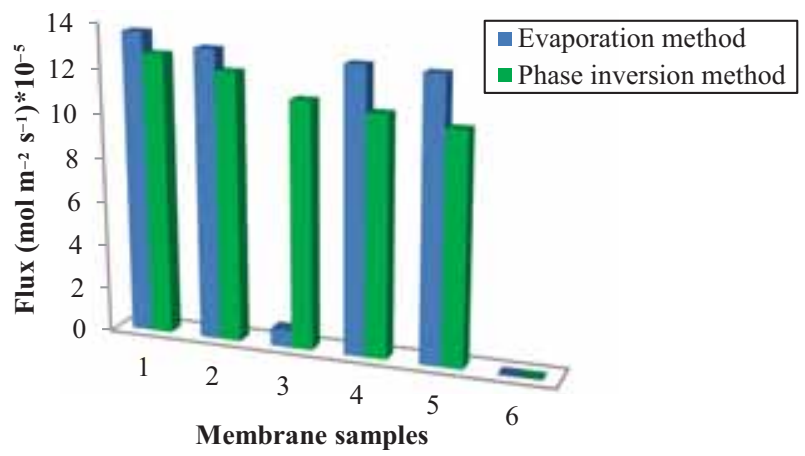

Figure 18. Effect of preparation method and blend ratio of polymers binder (SPPO:SPVC) on ionic flux of home-made cationexchange membranes.

strength of membranes were increased with decline in blending ratio (SPPO:SPVC) from samples 1-6. Also, the obtained data indicated that the mechanical strength of phase inversion samples was higher than evaporation samples. This can be attributed to the higher SPVC content (as a polymer with robust mechanical strength) in phase inversion samples than others due to the loss of SPPO in the water during membrane preparation (as mentioned before). Therefore, the decline of SPVC content results in a brittle and weaker membrane.
Table 2. Effect of binder ratios (SPPO:SPVC) on weight loss in the oxidative stability test for the prepared membranes.

\begin{tabular}{lcc}
\hline & \multicolumn{2}{c}{ Weight loss (\%) } \\
\cline { 2 - 3 } Sample's number & Evaporation method & Phase inversion method \\
\hline 1 & 13.08 & 12.85 \\
2 & 12.82 & 11.67 \\
3 & 14.43 & 11.03 \\
4 & 12.48 & 10.88 \\
5 & 11.26 & 10.80 \\
6 & 10.73 & 10.71 \\
\hline
\end{tabular}

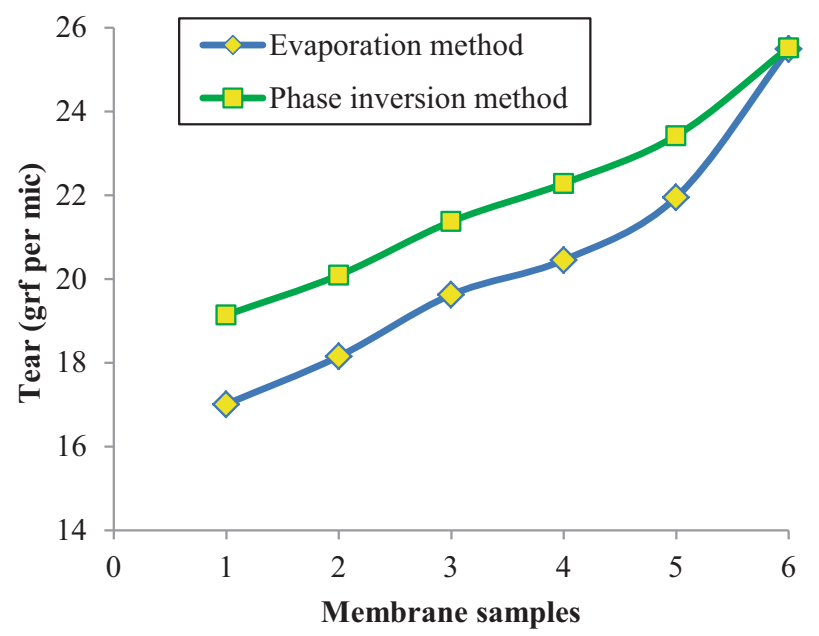

Figure 19. Effect of preparation method and binder ratios (SPPO:SPVC) on mechanical properties of the prepared membranes.

Table 3. Areal electrical resistance of prepared membranes with two preparation methods and blend ratios of polymers binder.

\begin{tabular}{|c|c|c|}
\hline \multirow{2}{*}{$\begin{array}{l}\text { Membrane } \\
\text { composition } \\
\text { (SPPO/SPVC) }\end{array}$} & \multicolumn{2}{|c|}{ Areal resistance $\left(\Omega \mathrm{cm}^{2}\right)$} \\
\hline & Evaporation method & Phase inversion method \\
\hline $70 / 30$ & 592.98 & 725.32 \\
\hline $60 / 40$ & 897.68 & 953.12 \\
\hline $50 / 50$ & $17,101.70$ & 1251.82 \\
\hline $40 / 60$ & 1437.54 & 1928.68 \\
\hline $30 / 70$ & 5031.84 & 5718.59 \\
\hline $0 / 100$ & $164,331.63$ & $164,549.74$ \\
\hline
\end{tabular}

\subsection{Electrical resistance}

Table 3 presents the effects of blend's ratio of polymers binder (SPPO:SPVC) and preparation method on areal resistance of the prepared membranes. In the majority of cases, the electrical resistance of the prepared membranes was decreased 
by increasing SPPO content in the casting solution. However, the areal resistance of the samples prepared by phase inversion method was higher compared to the samples prepared by evaporation method. This can be described by the IEC and functional groups content which provide the suitable ion conducting pathways throughout the membrane networks.

Moreover, when the SPVC content is high, not all of ion-exchange groups are available for ion transfer and the

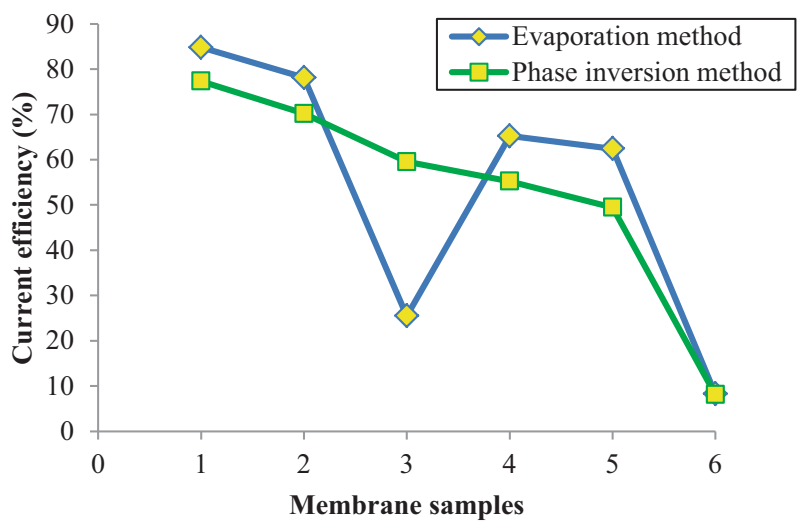

Figure 20. Effect of preparation method and polymers blend ratio on the current efficiency of the prepared membranes.
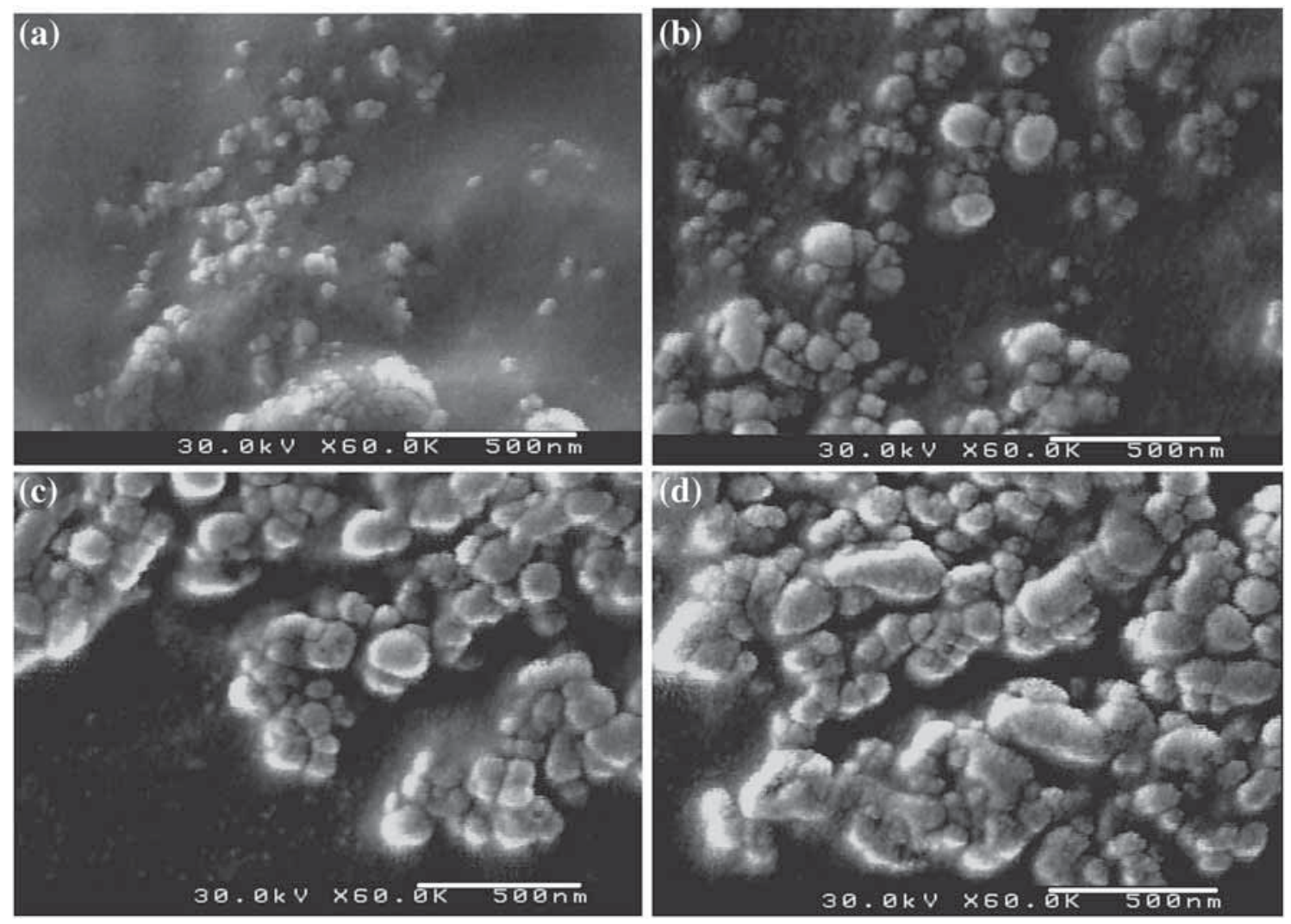

membrane has high resistance. Furthermore, an inverse relationship between areal resistance and FIC can be found. The higher FIC results in lower areal resistance due to the influence of a strong uniform electrical field in the vicinity of the membrane [25].

\subsection{Current efficiency}

Figure 20 shows the effect of polymers' blend ratio on the current efficiency of the prepared membranes. Similar trends were observed for the current efficiency, flux and ionic permeability. In both preparation methods, sample 1 presented the highest current efficiency. This can be due to the least areal electrical resistance and highest ionic permeability in this sample compared to others.

As expected, for the pure SPVC (sample 6) and prepared sample with evaporation method at $50 \%$ SPPO (sample 3 ), the current efficiency was decreased due to low ionic permeability and surface charge density in these membranes.

\subsection{Superior sample for preparation of nanocomposite membranes}

After the examination of morphology and electrochemical properties of the prepared IEMs, this study introduces the

Figure 21. Surface SEM images of nanocomposite membranes with various loadings of $\mathrm{Fe}_{2} \mathrm{O}_{3}$ nanoparticles: (a) $0.5 \mathrm{wt} \%$, (b) $1 \mathrm{wt} \%$, (c) $1.5 \mathrm{wt} \%$ and (d) $2 \mathrm{wt} \%$. 
sample prepared by evaporation method and 70\% SPPO with suitable oxidative stability, mechanical properties, ionic flux, permeability, permselectivity, transport number and high current efficiency as an applicable membrane. In the following, some nanocomposite membranes were prepared by $\mathrm{Fe}_{2} \mathrm{O}_{3}$ nanoparticles, in addition to the mentioned sample matrix (70:30) and their transport numbers were evaluated. The nanocomposite membranes were prepared at various filler concentrations ranged from 0.5 to $2 \mathrm{wt} \%$. SEM images of $\mathrm{SPPO}+\mathrm{SPVC} / \mathrm{Fe}_{2} \mathrm{O}_{3}$ are shown in figure 21 that confirm the suitable dispersion of nanoparticles in the polymeric matrices (except sample with $2 \mathrm{wt} \%$ additive loading). At $2 \mathrm{wt} \%$ $\mathrm{Fe}_{2} \mathrm{O}_{3}$ loading, the ferric oxide nanoparticles tend to be accumulated in the membrane matrix (figure 21d). The presence of the-OH groups on the surface of $\mathrm{Fe}_{2} \mathrm{O}_{3}$ nanoparticles is the main reason of their tendency to attract one another through hydrogen bonds and therefore, get agglomerated. The proposed mechanism of nanoparticles aggregation is exhibited schematically in figure 22.

\subsection{Transport properties of nanocomposite membranes}

Transport number and permselectivity of membranes are shown in figure 23. At first, both improved with the increase of additive loading to $1 \mathrm{wt} \%$. This behaviour can be described with respect to the surface properties of $\mathrm{Fe}_{2} \mathrm{O}_{3}$ nanoparticles. With the increment of additive loading (up to $1 \mathrm{wt} \%$ ), the ion pathways are partially filled with $\mathrm{Fe}_{2} \mathrm{O}_{3}$ nanoparticles

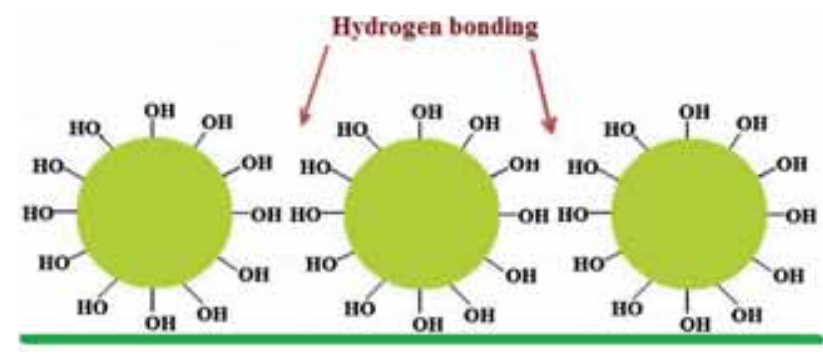

Figure 22. Proposed mechanism of nanoparticles aggregation.

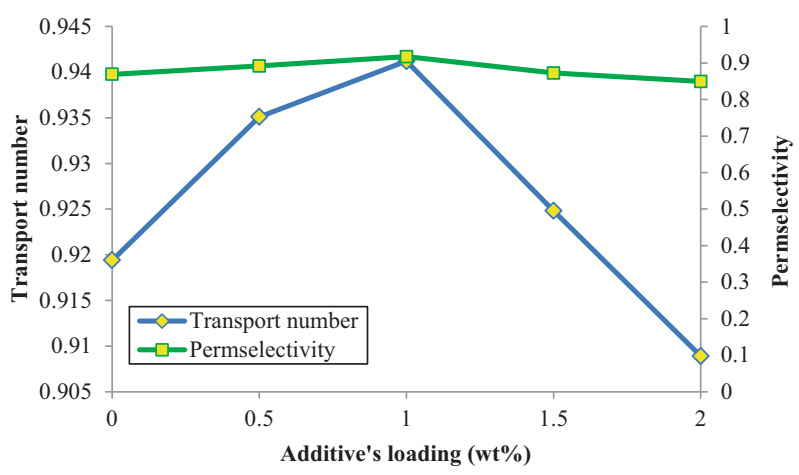

Figure 23. Permselectivity and transport number of prepared membranes with various nanoparticles loadings.
Table 4. Water contact angle of virgin and nanocomposite membranes.

\begin{tabular}{lc}
$\mathrm{Fe}_{2} \mathrm{O}_{3}$ nanoparticles loading $(\mathrm{wt} \%)$ & Water contact angle $\left({ }^{\circ}\right)$ \\
\hline 0 & $31.25( \pm 0.46)$ \\
0.5 & $29.18( \pm 0.53)$ \\
1 & $27.12( \pm 0.68)$ \\
1.5 & $26.34( \pm 0.45)$ \\
2 & $24.92( \pm 0.61)$ \\
\hline
\end{tabular}

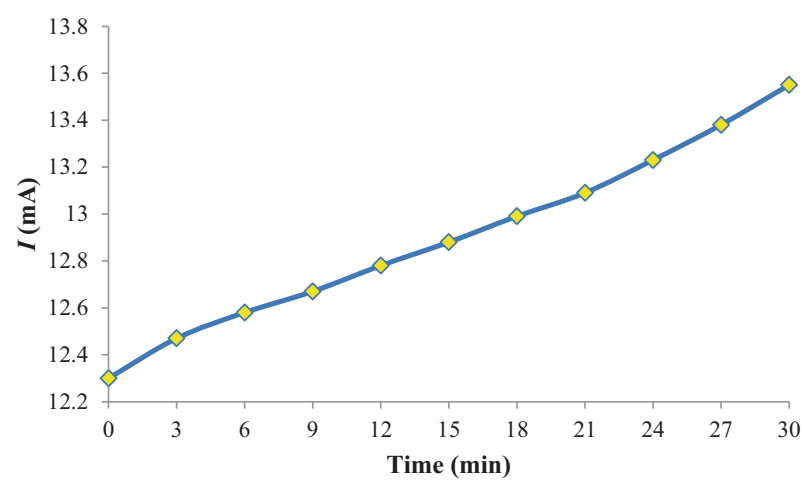

Figure 24. Variations of current intensity with time for the sample containing $1 \mathrm{wt} \% \mathrm{Fe}_{2} \mathrm{O}_{3}$ nanoparticles.

containing high surface hydroxyl groups [26] and so membrane channels are narrowed by them as space limiting factors. Therefore, improved control of pathways for ions traffic can be achieved, which leads to enhanced permselectivity and transport number.

Also, water contact angle of prepared nanocomposite membranes decreased compared to virgin (70:30) membrane (table 4). Higher the hydrophilicity, lower the water contact angle. This result is due to hydrophilicity of $\mathrm{Fe}_{2} \mathrm{O}_{3}$ nanoparticles, which exposes a large number of hydroxyl groups at the surface.

At higher filler concentration, more of the functional groups are surrounded and isolated by the $\mathrm{Fe}_{2} \mathrm{O}_{3}$ nanoparticles. Consequently, the membrane functional groups are partially inaccessible, which in turn leads to weaker transport properties [19].

The variations of current intensity with time for the sample containing $1 \mathrm{wt} \% \mathrm{Fe}_{2} \mathrm{O}_{3}$ nanoparticles are shown in figure 24 . As expected, by transferring of counter-ions to the cathodic section, the improvement of current intensity during the time can be observed.

A comparative report between general properties (transport numbers and water content) for prepared membranes and a standard Nafion membrane is shown in table 5. This table shows that the prepared nanocomposite sample has the desired properties when compared to others. 
Table 5. A comparative report between the prepared samples and a Nafion membrane.

\begin{tabular}{lcc} 
Membrane & Water content (\%) & Transport number \\
\hline Nafion 117 [27] & 18.9 & 0.93 \\
SPPO:SPVC (70:30) & 14.82 & 0.91 \\
SPPO:SPVC (70:30)/ & 21.73 & 0.94 \\
$\mathrm{Fe}_{2} \mathrm{O}_{3}(1 \mathrm{wt} \%)$ & & \\
\hline
\end{tabular}

\section{Conclusion}

The homogeneous cation exchange membranes based on SPPO and SPVC were prepared by phase inversion and evaporation methods. The prepared membranes by evaporation method exhibited higher efficiency and suitable electrochemical properties in comparison with phase inversion samples. For prepared membranes by both methods, the measurements indicated that water content and IEC were enhanced by increasing binder ratio (SPPO:SPVC) in the casting solution. Furthermore, the prepared membrane by evaporation method at 50:50 (SPPO:PVC) composition showed higher water content compared to membrane with 60:40 (sample 2) composition. For phase inversion samples, the results showed that membrane potential, permselectivity, transport number, surface charge density, ionic permeability and flux were decreased with decline in blend's ratio of polymers binder (SPPO:SPVC) from samples 1-6. For evaporation method samples the results revealed that membrane potential has a trend similar to FIC values. The decrease in FIC values leads to the decline in membrane surface charge density and conducting areas. The decrease of blending ratio (SPPO:SPVC) from 70:30 to 50:50 led to decrease in permselectivity, transport number, surface charge density, ionic permeability and flux of ions. These properties were increased with more decline of SPPO from 50 to $40 \%$. However, all the mentioned parameters were decreased again from sample 4 (40:60) to $6(0: 100)$ due to the decline in IEC and concentration of fixed charge on the membrane's surface.

For prepared membranes by both the methods, the mechanical strength of membranes was increased with decline in blending ratio (SPPO:SPVC) due to higher SPVC content as a polymer with robust mechanical strength. Also, the electrical resistance of the prepared membranes was increased with the decrease of SPPO in the casting solution. However, the prepared membrane by evaporation method at 50:50 (SPPO:SPVC) composition exhibited higher areal resistance compared to membranes with 40:60 (sample 4) and 30:70 (sample 5) compositions. As proven by the obtained experiment results, there was a straight relationship between current efficiency and ionic permeability. Also, the results showed that the addition of $\mathrm{Fe}_{2} \mathrm{O}_{3}$ nanoparticles to the membrane matrix has a considerable effect on the structure, hydrophilicity and properties of the IEMs, which can improve the transport number of membranes.

\section{Acknowledgement}

We are thankful to the Laboratory of Functional Membranes (University of Science and Technology of China) for providing SPPO.

\section{References}

[1] Garcia-Gabaldon M, Perez-Herranz V and Ortega E $2011 \mathrm{~J}$. Membr. Sci. 37165

[2] Li X, Wang Z, Lu H, Zhao C, Na H and Zhao C 2005 J. Membr. Sci. 254147

[3] Heidary F, Nemati Kharat A and Khodabakhshi A R 2016 J. Cluster Sci. 27193

[4] Xu T W, Yang W H and He B L 2002 Chin. J. Polym. Sci. 20 53

[5] Xu T W, Wu D and Wu L 2008 Prog. Polym. Sci. 33894

[6] Yu H and Xu T W 2006 J. Appl. Polym. Sci. 1002238

[7] Wu D, Wu L, Woo J J, Yun S H, Seo S J, Xu T W et al 2010 J. Membr. Sci. 348167

[8] Zhang X, Chen Y, Konsowa A H, Zhu X and Crittenden J C 2009 Sep. Purif. Technol. 7071

[9] Xu L and Lee H K 2009 J. Chromatogr. A1216 6549

[10] Xu T W, Yang W H and He B L 2001 Chem. Eng. Sci. 565343

[11] Xu T 2005 J. Membr. Sci. 2631

[12] Nagarale R K, Shahi V K, Thampy S K and Rangarajan R 2004 React. Funct. Polym. 61131

[13] Nagarale R K, Gohil G S, Shahi V K and Rangarajan R 2004 Colloid Surf. A251 133

[14] Shahi V K, Thampy S K and Rangarajan R 1999 J. Membr. Sci. 15877

[15] Nagarale R K, Shahi V K and Rangarajan R 2005 J. Membr. Sci. 24837

[16] Gohil G S, Binsu V V and Shahi V K 2006 J. Membr. Sci. 280 210

[17] Schauer J, Kudela V, Richau K and Mohr R 2006 Desalination 198256

[18] Khodabakhshi A R, Madaeni S S and Hosseini S M 2011 Sep. Purif. Technol. 77220

[19] Heidary F, Khodabakhshi A R and Nemati Kharat A 2016 Korean J. Chem. Eng. 331380

[20] Tanaka Y 2007 Ion exchange membranes: fundamentals and applications (Amsterdam: Elsevier)

[21] Nagarale R, Gohil G S, Shahi V K, Trivedi G and Rangarajan S R 2004 J. Colloid Interf. Sci. 277162

[22] Kerres J, Cui W, Disson R and Neubrand W 1998 J. Membr. Sci. 139211

[23] Kang M S, Choi Y J, Choi I J, Yoon T H and Moon S H 2003 J. Membr. Sci. 21639

[24] Hosseini S M, Madaeni S S and Khodabakhshi A R $2010 \mathrm{~J}$. Membr. Sci. 362550

[25] Balster J, Krupenko O, Pünt I, Stamatialis D F and Wessling M 2005 J. Membr. Sci. 263137

[26] Chen H, Li T, Zhang L, Wang R, Jiang F and Chen J 2015 J. Environ. Chem. Eng. 32022

[27] Kotera S, Piotrowskia P and Kerres J 1999 J. Membr. Sci. 153 83 